\title{
Extent of Yield Gap and Constraints in Different Adoption Level of Chickpea in Madhya Pradesh
}

\author{
R.S. Raghuwanshi ${ }^{1}$, Suresh Chawada ${ }^{1}$ and Ravi Singh Chouhan ${ }^{2 *}$ \\ ${ }^{1}$ Associate Professors and Student, College of Agriculture, Tikamgarh, Madhya Pradesh, India \\ ${ }^{2}$ Research Associate AER Centre, Jawaharlal Nehru Krishi Vishwa Vidyalaya, Jabalpur, Madhya Pradesh, India \\ "Corresponding author: rsraghuwanshi2012@gmail.com
}

\begin{abstract}
The study is formulated to assess the extent of yield gap at different adoption levels and identify the constraints responsible for the existing yield gap in chickpea production technology of Madhya Pradesh. The study was carried out in the Khargone district with 60 sample farmers form 5 villages in the state. The study reveals that adoption of improved production technology has lagged far behind. The chickpea productivity could be increased in the area through the judicious use of improved inputs and practices for that purpose. On the other hand, the proper use of improved technology and improved practices of chickpea production need to be demonstrated. Hence, farmers should given priority to use their resources on the basis of economic viability with proper management of their farm so that emphasis should be given on resources availability and their economic use. Economic study to be conducted suggests optimal cropping pattern and practices including recommendations for varying quantities of fertilizer applications under varying price and output situations.
\end{abstract}

Keywords: Khargone, farmers, fertilizer, production technology, chickpea, economic

The benefits of the new technology are largely expressed as increased yield, the first step is to estimate yield changes due to adoption of different level of technology, it's called yield gap. Yield gap refers to the difference between the potential yield (yield on progressive farms) and actual farm yield (realized on the general farmers' filed). These facts nevertheless, signify the broad scope for increasing the crop yields through proper application of inputs at the recommended levels and better management practices. Determination of the potential yield and gaps between potential and actual yields requires thorough understanding of crop growth and development, which in turn depends on several climatic, edaphic, hydrological, physiological and production management factors. This can be achieved by using high yielding management practices (Yang et al. 2008) and closing yield gaps between farmers' actual yield and potential yield (Cassman et al. 2003; Licker et al. 2010; Timan et al. 2011 and Muller et al. 2012). Madhya Pradesh is the major pulse producing state contributing a major share of $45.54 \%$ to the national chickpea production. In Madhya Pradesh the area under chickpea has remarkably increased from 1.49 $\mathrm{MH}$ in 1968-69 to 3.02 in 2015-16. Similarly production has also increased from 0.73 MT to 3.27 MT during the same period. The average yield of chickpea in the state found $1082 \mathrm{~kg} /$ hectare. (GoI, 2016)

It is important point to note that chickpea continues to be the largest consumed in home as well as industrial purpose comprising of about 50 per cent of the total pulses production of India. On the other hand, it is also noted that the productivity of chickpea is found to be low in comparison to their potential yield. It showed improvement in chickpea production is needed through conservation, diversification of agriculture and to enhance adoption level of improved chickpea production technology. So, to increase the productivity, particularly under rainfed chickpea growing regions is one of the major challenges and concern 
which need to be addressed on priority basis. Once the yield difference has been estimated, it is possible to calculate a value of increased yield and calculate the total value of increased production resulting from adoption of improved technology in crop production in the study area. It may also be important to obtain an estimate of the increased income for farmers who have adopted the new technology. Such an estimate will require good data on the variable costs of the technology. Estimates of the benefits of a new technology should be balanced against possible costs implied by changes in other parts of the farming system. The long-term sustainability of a new practice may also need to be examined when considering costs and benefits. Looking to above facts in mind, this particular study is formulated to assess the extent of yield gap at different adoption levels and identify the constraints responsible for the existing yield gap in chickpea production technology of Madhya Pradesh.

\section{Methodology}

Khargone district of Madhya Pradesh has been selected for the purpose of this study because chickpea is one of the main rabi pulse crops in the region. Three stage sampling technique was used for drawing the sample for the study. At the first stage, Khargone block in Khargone district was selected purposively due to most suitable area for chickpea crop. At the second stage, a list of important chickpea growing villages was prepared and 5 villages were selected randomly among them. At the third stage, a list of chickpea growing cultivators of each village was prepared and among them 60 farmers was selected randomly for the selection of respondents for the study. Thus, the sample was confined as 60 farmers form 5 villages (200) in a block of the Khargone district. The primary data was collected from selected respondents using pretested questionnaire, through survey method. The data was collected for the Agricultural year 20162017. In respect of technological status at farm level, the selected chickpea growers were classified into three categories with respect to level of adoption (low, moderate and high). Having identified the number of farmers under each category the indices of adoption was calculated as under:
Adoption index $(\%)=$

Adoption score obtained by respondent

Possible maximum score

For yield gap analysis the potential farm yield was considered which is obtainable on a farmer's field with the adoption of recommended chickpea production technology. The difference between the potential farm yield and actual farm yield is termed as a yield gap. In the study following yield gaps were considered:

- Gap I: Between demonstration farms and progressive farms.

- Gap II: Between progressive farms and average farmers practices.

- Gap III: Between progressive farmers' practices and least adopted farmers' practices.

\section{RESULTS AND DISCUSSION}

The yield gap at different adoption levels and constraints responsible for the existing yield gap in chickpea production technology in Madhya Pradesh were analyzed.

\section{Extent of yield gap}

The actual farm yield needs to be compared under different situations to be of more use for decision making. The most widely used term 'potential' yield is defined as the yield of chickpea which is obtainable on demonstration fields under farmers environments with the use of modern and recommended production inputs and practices giving maximum yield. In the present study, potential yield is treated as the yield realized by farmers through demonstrations laid by agricultural scientists by Zonal Research Station Khargone. The result of demonstration depicted that average yield on demonstration field with use of improved and recommended production practices was on an average $16.00 \mathrm{q} /$ ha (ranging from minimum 14.62 to $17.00 \mathrm{q} / \mathrm{ha}$ ). The difference between the potential farm yield and the average farm yield in different situation of technological status may be called as the yield gaps which are considered in the present study. The table 1 revealed quantification of yield gap between potential (demonstration farm) and 
Table 1: Average yield of chickpea under different situation

\begin{tabular}{rlcll}
\hline S. No. Situation & $\begin{array}{c}\text { Yield } \\
\text { (Q./Ha.) }\end{array}$ & Termed as & Remarks \\
\hline 1 & $\begin{array}{l}\text { Assured input supply } \\
\text { (demonstration farm) }\end{array}$ & 16.00 & Attainable & $\begin{array}{l}\text { Supply of recommended yield attributing inputs } \\
\text { assured, improved practices and farmers management. }\end{array}$ \\
2 & $\begin{array}{l}\text { High adoption package of } \\
\text { practices, (progressive farm) }\end{array}$ & 13.74 & $\begin{array}{l}\text { Technological } \\
\text { practices }\end{array}$ & $\begin{array}{l}\text { Farmers own resources with recommended use of } \\
\text { yield attributing inputs and management with normal } \\
\text { practices followed by progressive farmers in the area. }\end{array}$ \\
3 & $\begin{array}{l}\text { Farm used own practices } \\
\text { (moderate average in the area) }\end{array}$ & 12.15 & $\begin{array}{l}\text { General farm } \\
\text { practices } \\
\text { Poor farm } \\
\text { practices }\end{array}$ & $\begin{array}{l}\text { Farmers own resources with own practices and } \\
\text { moderate use of improved inputs. }\end{array}$ \\
$\begin{array}{l}\text { Poor farm practices } \\
\text { (traditional/least practices) } \\
\text { meager use of improved inputs. }\end{array}$ \\
\hline \begin{tabular}{l} 
Average yield \\
\hline
\end{tabular}
\end{tabular}

Source: Authors' own calculations.

Table 2: Magnitude of yield gap in chickpea production with different level of technological status

\begin{tabular}{|c|c|c|c|c|}
\hline \multirow[t]{2}{*}{ S. No. } & \multirow[t]{2}{*}{ Situation } & \multicolumn{2}{|c|}{ Extant of gap } & \multirow[t]{2}{*}{ Contributing factors } \\
\hline & & Q/Ha. & $\%$ & \\
\hline 1 & Attainable yield (Potential yield) & - & - & Best Management and resource used \\
\hline 2 & $\begin{array}{l}\text { Demonstration farms and progressive } \\
\text { farms (Feasible yield) }\end{array}$ & 2.26 & 16.45 & $\begin{array}{l}\text { Resource knowledge and high adoption of } \\
\text { improved production technology }\end{array}$ \\
\hline 3 & $\begin{array}{l}\text { Progressive farms and moderate average } \\
\text { farmers practices }\end{array}$ & 1.59 & 13.10 & Moderate adoption by general farmer In area \\
\hline 4 & $\begin{array}{l}\text { Progressive farmer and least adopter } \\
\text { farmers practices }\end{array}$ & 2.74 & 24.91 & Traditional practices Poor yield \\
\hline 5 & Overall average & 2.20 & 18.15 & Average yield gap \\
\hline
\end{tabular}

Source: Authors' own calculations.

actual farm situation (average farm) yield with different technological status.

It is observed that the yield obtained in demonstration field was the highest $16.00 \mathrm{q} / \mathrm{ha}$, while the average yield of chickpea was found to be $12.30 \mathrm{q} / \mathrm{h}$. The higher yield can be achieved by general farm condition also as demonstration was laid on farmers' field situation but in the supply of recommended yield attributing inputs assured and high management practices. From a compression among the yields between general farm conditions found to vary. The progressive or high adoption package of practices farms realized yield on an average $13.74 \mathrm{q} / \mathrm{ha}$. followed by moderate adoption farmers realized yield on an average $12.15 \mathrm{q} / \mathrm{ha}$. and least adoption farmers realized yield on an average $11.00 \mathrm{q} / \mathrm{ha}$. This yield variation was due to adoption of different level of improved production technology. Hence, study has given clear cut idea that with the fill-up of the gap in adoption of improved production technology one can reduce the yield gap also. In nut shell, it is concluded that the yield of chickpea positively increase with the increase of level of technology. The quantification of yield gap between potential farm and general farm in the area can be revealed in Table 2.

Results indicate that there exists a reservoir of untapped yield potential of chickpea in the area. The contributing factors as derived in the study show that nearly 16.45 per cent yield of the progressive farmers can be increased merely by improved management practices and with use of judicious chickpea improved yield attributing inputs like demonstrations' fields. The study also revealed that with the use of improved production inputs; the general "moderate adopter" farmers in the area can get additional average yield by 13.10 per cent as the progressive farms which are feasible in the area as actual yield gap. Traditional farmers (least adopter) also can increase their yield upto 24.91 per cent 
with the use of improved management practices as progressive farmers are practicing in the area.

From comparison of the chickpea yield realized by different situation of technical status in the area, it may be concluded small and poor farmers with use of traditional production practices recorded the lowest yield (11.00q/ha.). On the other hand, the demonstration yield which can be attainable by general farmers recorded the highest yield (16.00q/ ha.). The study also revealed that the yield of chickpea found to increase with the higher use of technological level. The yield gap was of the range from $1.59 \mathrm{q} / \mathrm{h}$ a to $2.74 \mathrm{q} / \mathrm{h}$ a in chickpea cultivation which can be realized by farmers through the use of proper management of resources and adoption of improved practices on their farms.

\section{Different adoption levels of chickpea production technology}

The main components of technological process or technological status at farm level of chickpea production in study area was represented in Table 3.

The data depicted that on average chickpea growers adopted only 73.49 per cent of recommended chickpea production technology at farm level. All the selected chickpea growers were divided into three groups as per their levels of adoption of chickpea production technology. According to this adoption scale, the "least adoption" level of technology (least adoption level i.e. upto 60.00\%) chickpea growers adopted overall 57.21 per cent of recommended technology followed by "moderate adoption" level chickpea growers (more than $60.00 \%-75.00 \%$ ) adopted overall 72.34 per cent of recommended technology and "high adoption" level chickpea growers (more than $75.00 \%$ ) adopted overall 90.93 per cent of recommended technology. The chickpea growers were not only required to assess the adoption pattern of the production technology, but also necessary to assess the level of adoption of each components of technology on the farm level for effective planning of transfer of recommended technology.

The detail of components wise technological status is identified as below:

\section{High yielding variety seed}

On an average chickpea growers adopted only 77.02 per cent of "high yielding variety seed for specific area based" in cultivation of chickpea. According to adoption scale, the high level of adopters adopted maximum level of "high yielding variety" (92.18 per cent) followed by moderate adoption level chickpea growers adopted 75.93 per cent and least adoption level chickpea growers adopted 62.96 per cent of "high yielding variety" seed on their farm as per specific area based recommendation.

\section{Sowing method}

An average chickpea grower adopted only 86.59 per cent of "sowing method" in cultivation of chickpea. According to adoption scale, the high level of adopters chickpea growers adopted maximum level of "sowing method" 94.30 per cent followed by

Table 3: Technological status at farm level of chickpea production (Adoption index)

\begin{tabular}{|c|c|c|c|c|c|}
\hline \multirow{2}{*}{ S. No. } & \multirow{2}{*}{ Component of technology } & \multicolumn{4}{|c|}{ Level of adoption (\%) } \\
\hline & & Least & Moderate & High & Average \\
\hline 1. & $\begin{array}{l}\text { High yielding variety seed for specific area based Gourav, JG-16, } \\
\text { JAKI-9218 }\end{array}$ & 62.96 & 75.93 & 92.18 & 77.02 \\
\hline 2. & Sowing method (Spacing 30 to $10 \mathrm{~cm}$ ) & 82.69 & 82.78 & 94.30 & 86.59 \\
\hline 3. & Seed treatment (Benomil + Thirum (1:1) @ $3 \mathrm{~g} / \mathrm{kg}$ ) & 25.00 & 68.03 & 91.01 & 61.35 \\
\hline 6. & Interculture operations as per specific needs & 32.41 & 64.55 & 90.53 & 62.50 \\
\hline 7. & Insect-pest control as recommended (Imidacloprid 17.8\%SL) & 55.21 & 62.50 & 90.28 & 69.33 \\
\hline 8. & Disease control (Dythen M 45, 0.3\% solution & 64.29 & 67.35 & 86.24 & 72.63 \\
\hline 9. & Irrigation (2 time) & 56.67 & 51.90 & 87.41 & 65.33 \\
\hline
\end{tabular}

Source: Authors' own calculations. 
moderate adoption level chickpea growers adopted 82.78 per cent and least adoption level chickpea growers adopted 82.69 per cent of "sowing method" on their farm as per recommendation.

\section{Seed treatment}

An average chickpea grower adopted only 61.35 per cent of "fungicide seed treatment" in cultivation of chickpea. According to adoption scale, the high level of adopters chickpea growers adopted maximum level of "fungicide seed treatment" 91.01 per cent followed by moderate adoption level chickpea growers adopted 68.03 per cent and least adoption level chickpea growers adopted 25.00 per cent of "fungicide seed treatment" on their farm as per recommendation.

\section{Inoculation with Rhizobium and PSB cultures}

An average chickpea grower adopted only 78.64 per cent of "culture inoculation" in cultivation of chickpea. According to adoption scale, the high level of adopters chickpea growers adopted maximum level of "culture inoculation" 88.89 per cent followed by moderate adoption level chickpea growers adopted 81.75 per cent and least adoption level chickpea growers adopted 65.28 per cent of "culture inoculation" on their farm as per recommendation.

\section{Fertilizer application}

An average chickpea grower adopted only 77.15 per cent of "fertilizer application" in cultivation of chickpea. According to adoption scale, the high level of adopters chickpea growers adopted maximum level of "fertilizer application" to the extent of 92.93 per cent followed by moderate adoption level chickpea growers adopted 87.01 per cent and least adoption level chickpea growers adopted 51.52 per cent of "fertilizer application" on their farm as per recommendation.

\section{Interculture operations}

An average chickpea grower adopted only 62.50 per cent of "interculture operations as per specific needs" in cultivation of chickpea. According to adoption scale, the high level of adopters chickpea growers adopted maximum level of "interculture operations as per specific needs" to the extent of
90.53 per cent followed by moderate adoption level chickpea growers adopted 64.55 per cent and least adoption level chickpea growers adopted 32.41 per cent of "interculture operations as per specific needs" on their farm as per recommendation.

\section{Insect pest control}

An average chickpea grower adopted only 69.33 per cent of "insect pest control" in cultivation of chickpea. According to adoption scale, the high level of adopters chickpea growers adopted maximum level of "insect pest control" i.e. 90.28 per cent followed by moderate adoption level chickpea growers adopted 62.50 per cent and least adoption level chickpea growers adopted 55.21 per cent of "insect pest control" on their farm as per recommendation.

\section{Disease control}

An average chickpea grower adopted only 72.63 per cent of "disease control measures" in cultivation of chickpea. According to adoption scale, the high level of adopters chickpea growers adopted maximum level of "disease control measures" i.e. 86.24 per cent followed by moderate adoption level chickpea growers adopted 67.35 per cent and least adoption level chickpea growers adopted 64.29 per cent of "disease control measures" on their farm as per recommendation.

\section{Irrigation practices}

Average chickpea growers adopted only 65.33 per cent of "irrigation practices" in cultivation of chickpea. According to adoption scale, the high level of adopters chickpea growers adopted maximum level of "irrigation practices" i.e. 87.41 per cent followed by moderate adoption level chickpea growers adopted 51.90 per cent and least adoption level chickpea growers adopted 56.67 per cent of "irrigation practices" on their farm as per recommendation.

\section{Constraints responsible for the existing yield gap}

As observed in study that in general the productivity of chickpea is low as compared to high potential yield existed in the area. This yield gap could be due to various reasons which have to be identified 
Table 4: Production constraints identified by chickpea growers for existing yield gap

\begin{tabular}{|c|c|c|c|c|}
\hline S. No. & Constraints & $\begin{array}{c}\text { Frequency } \\
\quad \mathrm{N}=60\end{array}$ & $\%$ & Rank \\
\hline A. & Biological constraints & & & \\
\hline 1 & Non adoption of high yielding varieties. & 32 & 53.33 & iv $^{\text {th }}$ \\
\hline 2 & Weed infestation & 20 & 33.33 & vii $^{\text {th }}$ \\
\hline 3 & Incidence of insect pests & 45 & $75.00^{*}$ & $\mathrm{i}^{\mathrm{st}}$ \\
\hline 4 & Incidence of diseases & 25 & 41.67 & $\mathrm{vi}^{\mathrm{ith}}$ \\
\hline 5 & Water management & 29 & 48.33 & $\mathrm{v}^{\text {th }}$ \\
\hline 6 & Amount of rainfall received & 38 & $63.33^{*}$ & $\mathrm{ii}^{\text {nd }}$ \\
\hline \multirow[t]{2}{*}{7} & Soil fertility variation & 35 & $58.33^{*}$ & $\mathrm{iii}^{\mathrm{rd}}$ \\
\hline & Average & 32 & 53.33 & \\
\hline B. & Socio economic and technological constraints & & & \\
\hline 1 & Lack of own funds & 38 & $63.33^{*}$ & $i v^{\text {th }}$ \\
\hline 2 & Lack of credit facilities & 15 & 25.00 & $x^{\text {th }}$ \\
\hline 3 & Traditional belief & 20 & 33.33 & $i x^{\text {th }}$ \\
\hline 4 & High cost of inputs & 43 & $71.67^{*}$ & $i^{\text {st }}$ \\
\hline 5 & Lack of technical knowledge & 40 & $66.67^{*}$ & $\mathrm{ii}^{\text {nd }}$ \\
\hline 6 & Non availability of inputs in time & 37 & $61.67^{*}$ & $\mathrm{v}^{\text {th }}$ \\
\hline 7 & Non interested to high investment & 30 & 50.00 & vii $^{\text {th }}$ \\
\hline 8 & Lack of trained skilled labour & 33 & $55.00^{*}$ & $\mathrm{vi}^{\text {th }}$ \\
\hline 9 & Lack of training and guidance & 25 & 41.67 & viiith $^{\text {th }}$ \\
\hline \multirow[t]{2}{*}{10} & Continued crop failure & 39 & $65.00^{*}$ & $\mathrm{iii}^{\mathrm{rd}}$ \\
\hline & Average & 32 & 53.33 & \\
\hline
\end{tabular}

*higher than average value.

to make strategy for improvement in chickpea production and to reap the optimum profit. The various constraints confronted by chickpea growers in the study area regarding existing yield gap and non adoption of improved chickpea production technology the same are presented in Table 4.

The constraints confronted by chickpea growers in yield gap was due to mainly biological constraint and non adoption of improved chickpea production technology due to socio economic and technological constraint on their farm as partial level or non judicious level of input utilization were considered into two groups i.e. "biological constraints" and "socio economic and technological constraint". The Incidence of insect pest and diseases were found to be the major Biological constraint $(75.00 \%)$ followed by Amount of rainfall received (63.33\%), Soil fertility variation $(58.33 \%)$, Non adoption of high yielding varieties (53.33\%), Water management $(48.33 \%)$ and Weed infestation $(33.33 \%)$ respectively. The High cost of inputs 71.67 per cent followed by lack of technical knowledge $(66.67 \%)$, continued crop failure $(65.00 \%)$, lack of own funds $(63.33 \%)$, non availability of inputs in time $(61.67 \%)$, lack of trained skilled labour $(55.00 \%)$, non interested to high investment $(50.00 \%)$, lack of training and guidance $(41.67 \%)$, traditional belief $(33.33 \%)$ lack of credit facilities $(25.00 \%)$ were found to be the major constraints related to the Socio economic and technological issue.

\section{CONCLUSION}

The adoption of improved production technology has lagged far behind. The chickpea productivity could be increased in the area through the judicious use of improved inputs and practices for that purpose. On the other hand, the proper use of improved technology and improved practices of chickpea production need to be demonstrated. Hence, farmers should given priority to use their resources on the basis of economic viability with proper management of their farm so that emphasis should be given on resources availability and their economic use. chickpea production technology and 
its related skill orientated regular training should be arranged for the cultivators, so that available capital and resources can optimally be used in chickpea production even in the sphere of education and extension works emphasis needs to be laid on enhancing productive capacity of the population and the agricultural field. Agricultural research institutions should be taken varietals improvement and development of suitable agronomic practices for varying soils and geographic situations. Economic study to be conducted suggests optimal cropping pattern and practices including recommendations for varying quantities of fertilizer applications under varying price and output situations. Extensive research on promising varieties and cropping practices by joint teams of research and extension workers to be done.

\section{REFERENCES}

Cassman, Kenneth G., Dobermann, Achim R., Walters, Daniel T. and Yang, Haishun, 2003. "Meeting Cereal Demand While Protecting Natural Resources and Improving Environmental Quality". Agronomy \& Horticulture -Faculty Publications, pp. 318.
Government of India 2016. Agricultural statistics at a glance. Directorate of Economics and Statistics, Department of Agriculture and Cooperation, Ministry of Agriculture, New Delhi.

Licker, R., Johnston, M., Foley, J.A., Barford, C., Kucharik, C.J. and Monfreda, C. et al. 2010. Mind the gap: how do climate and agricultural management explain the 'yield gap' of croplands around the world? Glob. Ecol. Biogeogr., 19: 769-782.

Mueller, N.D., Gerber, J.S., Johnston, M., Ray, D.K., Ramankutty N. and Foley J.A. 2012. Closing yield gaps through nutrient and water management. Nature, 490: 254-257.

Tilman, D., Balzer, C., Hill, J. and Befort, B.L. 2011. Global food demand and the sustainable intensification of agriculture. Proc. Natl. Acad. Sci. U.S.A. 108: 20260-20264.

Yang, W., Peng, S., Laza, R.C., Visperas, R.M. and DionisioSese, M. 2008. Yield gap analysis between dry and wet season rice crop grown under high-yielding management conditions. Agron. J., 100: 1390-1395. 
